\title{
System Sizing for Solar Powered Sustainable Energy System Designed for Domestic Users
}

\author{
Ewen Constant ${ }^{*} \dagger$, Kary Thanapalan* Mark Bowkett* \\ ${ }^{*}$ Faculty of Computing, Engineering \& Science, University of South Wales, Pontypridd CF37 1DL, UK \\ Tel : +44 (0) 14434 82211; E-mail: Ewen.Constant@Southwales.ac.uk
}

\begin{abstract}
This paper provides an energy capture and storage analysis based on domestic applications. The work focusses on system sizing based on geographic location and is in the interest of a grid connected domestic user. It is concerned with the capture storage and use of electricity post meter. The hypothesis is to provide a net zero energy bill to the consumer by managing the flow of electricity into and out of the grid, whilst significantly reducing solar PV payback periods.
\end{abstract}

Keywords: Energy management, Domestic Energy storage, domestic consumption, solar energy, self-sustainable.

\section{INTRODUCTION}

This work is formed of three parts that are linked by the common topic of energy storage and its reuse. It initially discusses a systematic approach for the development of a solar powered self-sustainable energy system. Its premise is to develop an energy system that would allow an energy user to have a net zero energy bill, this could be further development to encompass users in remote locations which are not connected to mains energy systems. A self-sustainable energy system configuration is of interest to many groups and users, and as the supply of fossil fuels runs down they will have to become more widely used and accepted methods for energy capture storage and use.

This work intends to prove a more cost effective system other than grid connected systems that are available and provide cost effective solutions to consumers. This research investigates typical selfsustainable energy system configuration and looks to develop a performance optimisation model. The potential benefits of such a system design is investigated using data collected at three specific location and the performance of the system under variable conditions are determined. The paper goes onto describe an optimal design and implementation of an efficient selfsustainable energy system.

A system sizing model is also presented to enable consumers to accurately size the solar photo-voltaic (PV) systems needed in combination with a battery energy storage system (BESS) to minimise household bills. The proposition is that consumers can avoid selling energy at 4pence per kWh, only to buy it back when they come home from work at 14.17 pence per $\mathrm{kWh}$.
The combination of solar PV cells combined with a BESS carries great promise for a cleaner, more efficient energy future. It allows domestic users the opportunities to significantly reduce their bills, reduce their carbon footprint reduce the payback periods for standalone solar PV systems and finally avoid the high costs of dynamic electricity pricing, which is an inevitable side effect of SMART metering.

A photovoltaic array is considered as the main power source to the system. Solar PV systems are common and widely accepted in the UK, they provide the only realistic home energy generating possibilities for the majority of homeowners.

A self-managed highly sustainable and environmentally sound approach for consumers to manage their energy will have a fundamental role to play in addressing issues of reducing cost and maximising self-sufficiency.

In the UK we have very long payback rates for Solar PV systems, which is a hurdle to implementation, with the addition of a BESS we can significantly reduce the payback by around 5 years.

\section{SYSTEM STRUCTURE}

There are three distinct areas to be considered and researched, whilst developing a sustainable grid connected domestic energy system for consumers. In order to maximise the potential for a net zero electricity bill, analysis must be carried out to maximise opportunities in the capture, storage and management of energy. 
a) Capture of energy

We have previously researched [9] and found that the most efficient method of capturing energy for a domestic user is via photovoltaic PV cells, and we continue this theme in our further research.

b) Storage of energy

The storage medium to be considered is via batteries, and whilst we consider that lead acid batteries are still ahead of the game in terms of energy storage / cost comparison, lithium Ion continues to reduce in price, and we are approaching a position where li-ion are able to compete on price.

c) Demand side management.

Concerning the demand side management we are discussing the development of a new system, tailored for domestic use. We are not discussing SMART meters, which are of no use to the majority of domestic consumers. In the UK a domestic energy consumer is not allowed to be a net producer of electricity, and hence a consumer cannot be in a position where the energies companies actually pay the consumer for energy production. Thus, a system needs to be developed, where the consumer has the minimal amount to pay, ideally a bill in tens of pounds, or so close to a net bill of zero that it is negligible. It will sit inside the consumers home, and manage captured and stored energy, as well as interfacing with the grid connection in order to feed-in and draw electricity from the grid.

To this end, we have been researching the use of Solar PV systems combined with a home energy management system, capable of minimising the cost to consumers [2]. This entailed being grid connected, to minimise the size of the BESS, and to ensure a guaranteed supply of energy to the consumer. We believe that this grid security is a key factor in establishing a successful system, as the majority of consumers find the prospect of being off grid very daunting. We also need to 'store' energy in the grid, during times of over production for the times we know our generation capacity cannot meet demand, that is, during the winter months.

The common photovoltaic (PV) system as previously presented [1] will have the following structure, which are PV modules, battery pack, power management system and load (see, Figure 1).

We have established a mobile stand-alone system can be scaled to support a full domestic application [2] and our work on off grid systems [3] enables us to establish our preferred energy storage medium, which will be lead acid, as it currently has a cost advantage over lithium [4]. The switch to lithium however would looks inevitable in the near future as the cost of lithium continues to decline.

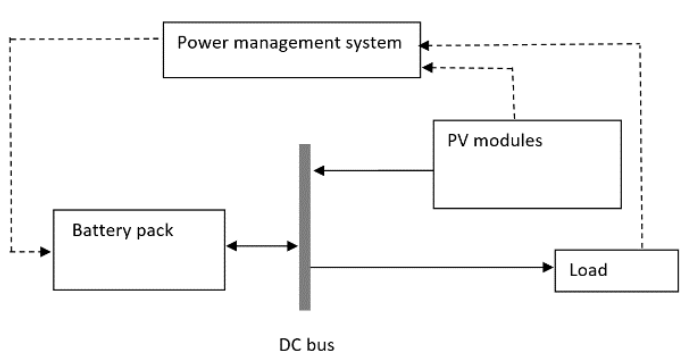

Figure.1. Solar powered energy and storage system [1]

The location for the research has focused on three distinct areas, Plymouth on the South West Coast of England, St Athan in the Vale of Glamorgan in South Wales and Nottingham in the North Midlands of England. The choice of location was to give a broad geographic spread to the sizing algorithms whilst validating the calculations.

\section{METHODOLOGY}

The maximum panel size that can fit onto a standard roof of a terraced house varies between 10 and 16 panels, in the UK. There is also a financial threshold at 16 panels where the feed in tariff (FIT) drops, most consumers are restricted by roof space, hence it is commercially sensible to restrict the installation to 16 panels. The potential of electricity generation is calculated by considering the number of panels, the time of day, the demand, which is broken into weekday and weekend, the irradiance, irradiance losses, and system losses. We can simplify this into a demand and supply equations (1) and (2):

$$
\begin{aligned}
& P_{P}=S_{P V} \cdot N \cdot\left(\zeta_{S} \cdot K\right) \\
& \text { and } \\
& P_{D}=P_{D A}-P_{A V}
\end{aligned}
$$

For the supply we have, Pp this is the overall power produced by the system, $\mathrm{N}$ is the number of panels, $\mathrm{Spv}$ is the panel size, $\zeta \mathrm{s}$ is the system efficiency and relates to the efficiency of the solar panels. $\mathrm{K}$ is the losses in the system. For the demand we have $\mathrm{P}_{\mathrm{P}}$ power produced and can be a positive or negative number, $\mathrm{P}_{\mathrm{DA}}$ demand and $\mathrm{P}_{\mathrm{AV}}$ is the available power, which is a function of the average irradiance and system losses.

The variability of demand is well documented and average demand profiles for various regions of the UK are publicly available [5]. The average demand profile $\mathrm{P}_{\mathrm{DA}}$ for St Athan is shown in Figure 2 as the dotted line below, and the generation profiles for various capacities are overlaid. Clearly, we can see the possibilities of overproduction between March and October is achievable with a variety of generation profiles. 


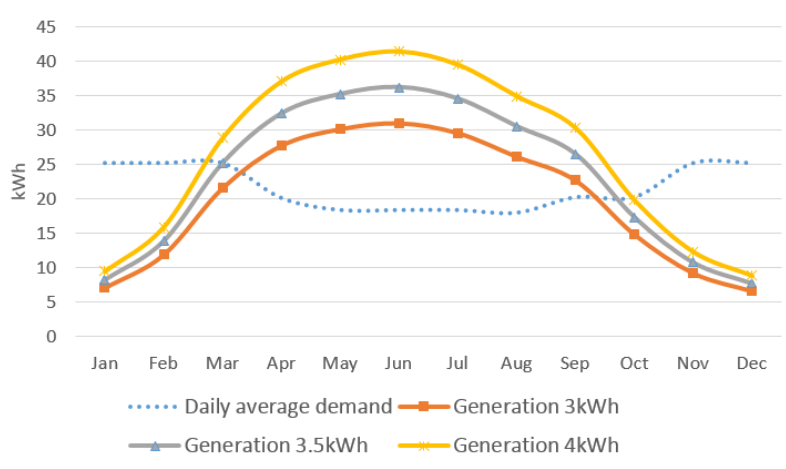

Fig.2. Average monthly demand and generation profiles

From equations (1) and (2) we can establish a profile for determining power produced $\mathrm{P}_{\mathrm{P}}(\mathrm{kW})$ from a known set of constant's and variables. From this we can establish an annual Figure for surplus energy production for various systems based on an average consumption Figure of consumers. Table 1 shows an example of data from $\mathrm{St}$ Athans in South Wales.

\begin{tabular}{|c|c|c|c|c|c|c|c|c|}
\hline & 10 & Panel & 12 & Panel & 14 & Panel & 16 & Panel \\
\hline & WD & WE & WD & WE & WD & WE & WD & WE \\
\hline Jan & 0.12 & 0.00 & \begin{tabular}{|l|}
0.49 \\
\end{tabular} & 0.00 & \begin{tabular}{|l|}
0.94 \\
\end{tabular} & 0.23 & 1.44 & 0.64 \\
\hline Feb & 1.19 & 0.38 & 1.99 & 1.14 & \begin{tabular}{|l|} 
\\
\end{tabular} & 1.99 & 3.72 & 2.89 \\
\hline Mar & 4.04 & 3.30 & 5.67 & 4.97 & \begin{tabular}{|l|}
7.36 \\
\end{tabular} & 6.70 & 9.09 & 8.42 \\
\hline Apr & 6.82 & 6.18 & 9.03 & 8.39 & 11.27 & 10.64 & 13.53 & 12.90 \\
\hline May & 7.70 & 7.01 & 10.08 & 9.41 & 12.50 & 11.82 & 14.92 & 14.27 \\
\hline Jun & 7.85 & 7.18 & 10.31 & 9.63 & 12.77 & 12.12 & 15.27 & 14.62 \\
\hline Jul & 7.39 & 6.71 & \begin{tabular}{|l|}
9.73 \\
\end{tabular} & 9.06 & 12.09 & 11.42 & 14.47 & 13.82 \\
\hline Aug & 6.36 & 5.97 & \begin{tabular}{|l|}
8.43 \\
\end{tabular} & 8.06 & 10.53 & 10.17 & 12.64 & 12.28 \\
\hline Sep & 5.12 & 4.57 & 6.91 & 6.37 & 8.73 & 8.21 & 10.58 & 10.06 \\
\hline Oct & 2.57 & 1.89 & \begin{tabular}{|l|}
3.68 \\
\end{tabular} & 3.04 & \begin{tabular}{|l|}
4.83 \\
\end{tabular} & 4.21 & 6.01 & 5.40 \\
\hline Nov & 0.58 & 0.03 & 1.18 & 0.40 & 1.81 & 0.98 & 2.48 & 1.64 \\
\hline Dec & 0.08 & 0.00 & 0.40 & 0.00 & 0.82 & 0.16 & 1.26 & 0.51 \\
\hline & \multicolumn{2}{|c|}{1468} & \multicolumn{2}{|c|}{2012} & \multicolumn{2}{|c|}{2576} & \multicolumn{2}{|c|}{3151} \\
\hline
\end{tabular}

Table 1. Daily surplus energy production ' $v$ ' system size.

Table 1 represents the daily surplus energy available to store in a BESS, and can be visualised in Figure 3, as we can see there is an almost linear relationship between number of panels and excess energy available to our system. Excess energy being the difference between generated capacity and demand. This data is used to size the battery pack, if we consider a 16 panel system, we need to be able to store a daily surplus of $15.27 \mathrm{kWh}$ of energy.

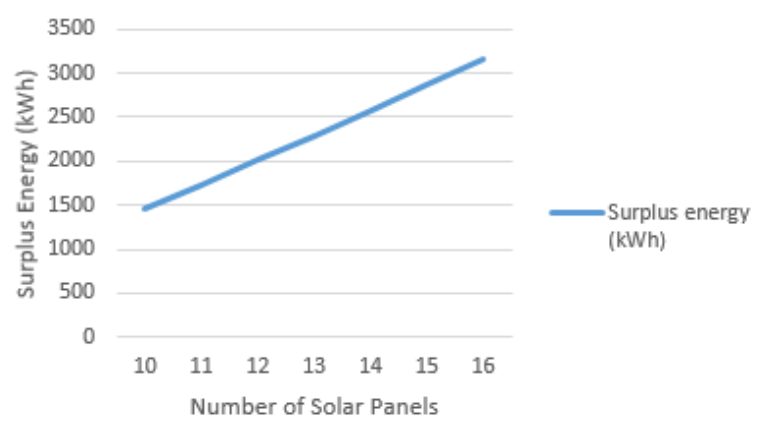

Figure. 3. PV Panel quantity 'v' Excess energy available.
However the majority of surplus energy is produced between normal working hours, and we need to capture this energy to reuse it when the consumer returns from work. This is especially pertinent in the winter, even through the darkest months of the year, the installation is capable of producing excess energy that is fed into a BESS. Shown in Figure 4, whilst during the winter months it isn't enough to support the requirements of the household we do not want to sell this energy to the grid at greatly reduced prices, only to buy it back later the same day.

It can show that if the consumer stores the excess energy, and bills are calculated over a 12 month period, we can significantly reduce the cost of domestic electricity. Our model shows that in the South of England there is a break even point very close to 16 panels under idealised conditions, see Figure 5. In the south Wales region, we can reduce bills to around $£ 48 /$ year and in the North Midlands of England, we can reduce the annual bill to around $£ 115 /$ year.

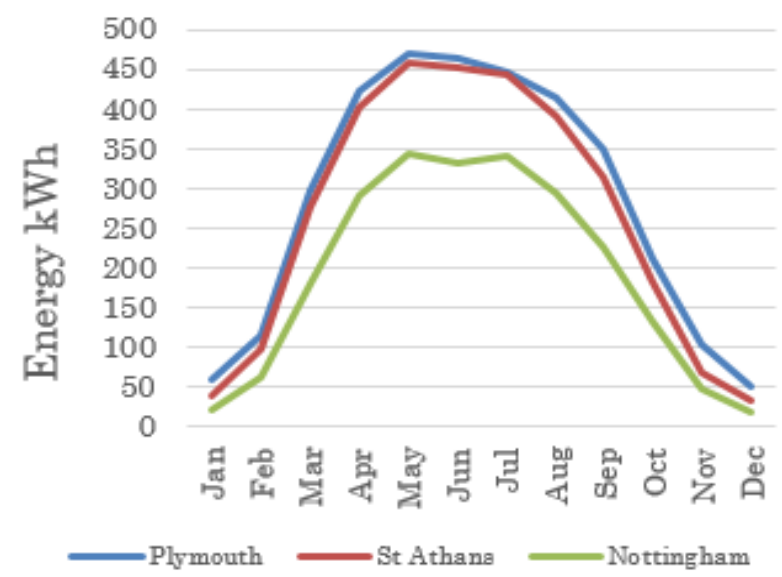

Figure. 4. Surplus energy 'v' Time of Year

Figure 5 also shows that as we add more panels to the system, we continue to reduce the overall cost to the consumer. It also highlights regional variations in the UK, primarily due to geographic changes in irradiance. We can see that with a 16 panel system, we almost break even on an annual basis in the South West of England, saving the consumer over $£ 500 /$ year in electricity. Whilst in Nottingham a 16 panel system has an annual cost of around $£ 150$, but only produces around $£ 35$ from FIT. However, this is still a significant saving over the approximate $£ 630$ of energy consumed every year.

When we combine our savings with our initial investment of a HESS Figure 6, we can construct our payback periods. What is interesting in Figure 6 is that due to the regional variations in both solar irradiance, the amount of daylight per region and the electricity demand due to climatic conditions, this leaves us with very similar payback periods for the three regions chosen. 


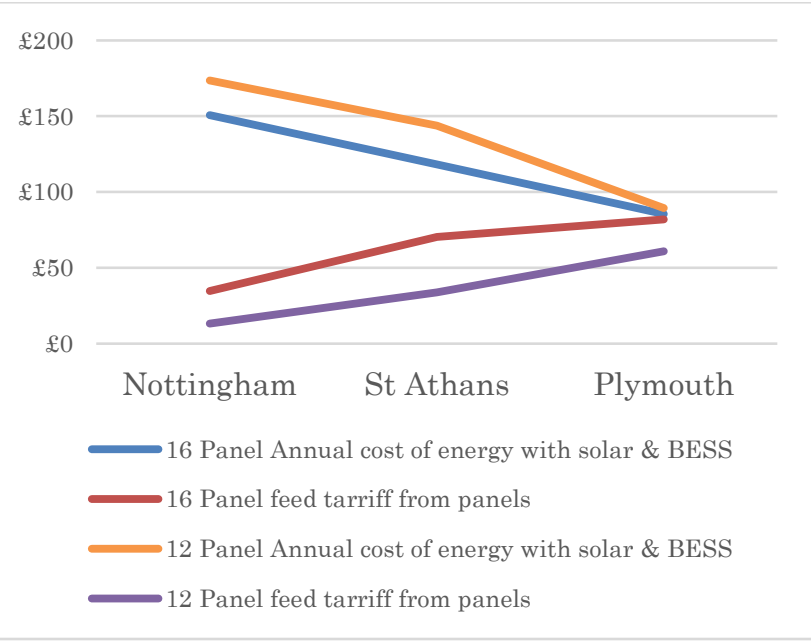

Figure. 5. Cost analysis / break even indicator

The payback period of a current solar powered system alone can be shown to be in the region of 21 years, this is primarily due to over production being fed in the grid, with a BESS and Solar PV system we can reduce this to around 15 years. Key to the success of this project however will be the development of a demand side management system (DSMS).

PV SYstem Payback 'v' BESS \& PV System Payback

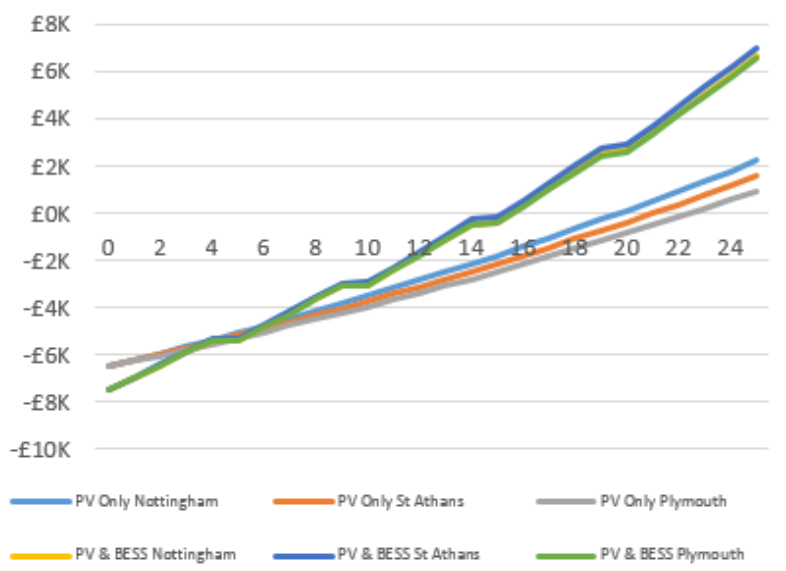

Figure. 6. Payback periods.

\section{DEMAND SIDE MANAGEMENT SYSTEM (DSMS)}

According to the common photovoltaic (PV) - battery system architecture (see Figure 1), the other subsystem is the power management system. The key role of the power management system is to make full use of the power generated from solar irradiation and minimising the use of grid fed electricity by maximising the stored energy in the battery pack. Therefore, with carefully selected system components, all the power generated by the solar PV array will be used to support the load demand, charge the battery pack, or feed energy into the grid.
Currently energy providers in the UK are pushing smart meters, these are of very little use to the consumer but provide detailed consumption data to the energy companies, the bias in the system is of note, demand and use of electricity is not set up for the benefit of the domestic user. Current estimates are that the introduction of smart meters across Europe will cost $€ 51$ billion [6].

This investment by energy companies has to be recouped, they are doing this by eliminating meter reading costs, permitting remote connect/disconnect of service, and will ultimately lead to dynamic energy pricing. These operational benefits represent cost reductions, rather than new or innovative products that could be beneficial to the customer, in short, the current trend to move towards smart meters is of no tangible benefit to the consumer, and this type of smart meter is not suitable for the management of the system proposed.

The consumer needs a new management system that will sit in front of any current meter, ie for the benefit of the consumer. It will need to manage flow of energy around the domestic system, drawing on the grid to supplement the household demands rather being reliant on it. It has to be intelligent enough to know that when electricity needs to be drawn from the grid, it will need to replace every $\mathrm{kWh}$ hour used with three $\mathrm{kWh}$ of generation to ensure that the consumer is not faced with any energy bills, assuming the feed in tariff is approximately $1 / 3$ that of the demand tariff.

There are currently solar PV and BESS management systems on the market, and they can be bought on the internet for as little as $£ 80$, but these are not suitable to manage the complex data that is required to ensure a net zero bill.

The use of an energy management system, is discussed in this work and the requirements of such a system are clearly defined, there is room for future research work to investigate and develop an advanced energy management system for domestic applications. One such example is CIRCE Energy Box developed by Fernández et al,2018 [7]

\section{DISCUSSION}

The intention of this research is to expose the benefit to consumers to fit a BESS rather than fitting solar panels alone. There are three distinct areas to be considered in a system of this nature. The capture of energy, solar PV being the only viable option, storage of energy, much research has gone into this area, and will continue to be done as the cost benefit analysis of lead acid systems continues to be eroded by the reducing price of lithium ion cells.

The demand side management of our proposal needs to be built and developed, it is the one area that is currently 
unavailable. Off grid management, systems are capable of carrying out the majority of the work, but intelligent grid interfacing is required for the success of this proposal, as we need to ensure energy security to make it a viable proposition.

Panel sizing has to be the maximum possible to ensure enhanced payback and reduced costs, and a $4 \mathrm{kWh}$ system is proposed due to limitation over size, however, it is noted that larger system will be less reliant on idealised conditions.

A math model has been developed to describe the demand and supply requirements, and this needs to be further developed into suitable programme to allow system sizing to be done quickly and efficiently.

There is an additional on cost of the batteries and the control system to consider, and an estimated Figure has been factored into the calculations. It is clear to the authors that there are significant benefits in reducing the payback periods and reducing the reliance on grid fed energy.

Whilst considering the sizing of the photovoltaic cells, the location nominated for research was Plymouth, St Athans and Nottingham, the demand data was obtained from the United Kingdom Energy Research Centre (UKERC), and finally the orientation data sets from the European Joint Research Centre (JRC).

\section{CONCLUSION}

From the results and analysis presented in the paper, in particular the cost - benefit analysis the proposal to produce a HESS which is a financially viable are clearly defined.

A math model for estimating system sizing is presented and a detailed analysis of the results show a significant financial benefit to consumers to fit a HESS.

System sizing and cost analysis are carried out with reference to specific locations and the best configuration for the case has been identified. To store the surplus energy lead-acid batteries are currently the most suitable energy storage option.

What is implied but not expressly discussed are the environmental benefits of fitting a system of this nature, significantly reducing the energy demand on grid supplied energy. With Hinkley Point $\mathrm{C}$ power station set to cost UK tax payers $£ 20.3$ Billion [8] this could fund 2.7 Million HESS systems reducing energy demand by 10.66 Billion $\mathrm{kWh} /$ year. Hinkley point $\mathrm{C}$ has a generation capacity of $3260 \mathrm{MW}_{\mathrm{e}}$. and would therefore be mothballed.

\section{REFERENCES}

[1] Constant, E., Thanapalan, K., Bowkett, M. (2018). Optimal energy storage evaluation of a solar powered sustainable energy system. In the Proceedings of the $5^{\text {th }}$ IEEE- SICE International Symposium on Control Systems, Tokyo, Japan, March 9-11, 2018.

[2] Constant, E., Thanapalan, K., Bowkett, M. (2018). Capture and storage of PV-Energy for domestic consumption. In the Proceedings of the $5^{\text {th }}$ IEEE International Conference on Control, Decision and Information Technologies (CoDIT'18), Thessaloniki, Greece, April 10 -13, 2018.

[3] Constant, E., Thanapalan, K., Bowkett, M. (2018) Development of a solar powered self-sustainable energy system. Renewable Energy and Power Quality Journal, Vol 16, 299, 2018 .

[4] K. Thanapalan, F. Zhang, S. Carr, G. Premier, A. Guwy, J. Maddy, 'An overview of renewable energy technologies and hydrogen economy' Renewable Energy and Power Quality Journal, vol. 1, no. 11, pp. 322:1-6, March. 2013

[5] Regional electricity consumption data https://www.gov.uk/government/collections/sub-nationalelectricity-consumption-data : accessed 15/02/2018

[6] Dynamic pricing of electricity: www.fes.nationalgrid.com/media/1287/more-thoughts-v12.pdf accessed 18/03/2018

[7] Fernández, G. Bludszuweit, H. Torres, J. Almajano, J. Machín, I. Sanz, J. Serrano, R. Garín, M. 'Optimal demand-side management with a multi-technology battery storage system' Presented at International Conference on Renewable Energies and Power Quality (ICREPQ'18) Salamanca (Spain), 21 ${ }^{\text {st }}$ March, 2018

[8] Cost of energy Hinkley Point C Power Station https://www.theguardian.com/news/2017/dec/21/hinkleypoint-c-dreadful-deal-behind-worlds-most-expensivepower-plant : Accessed 15/03/2018.

[9] Constant, E,. Capture and storage of renewable energy for demand side management of energy consumption. Dissertation submitted to University of South Wales as part of MSc Mechanical Engineering. April 2018 